\title{
Tiña negra (tinea nigra): comunicación de un caso alóctono en Chile
}

\author{
Raúl Cabrera, Natalia Sabatini, Mauricio Urrutia y Rodrigo Sepúlveda
}

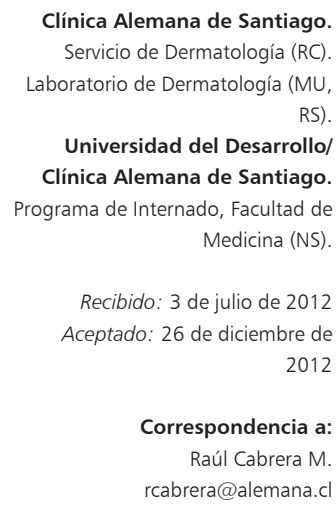

Clínica Alemana de Santiago. Servicio de Dermatología (RC). Laboratorio de Dermatología (MU, Universidad del Desarrollo/ Clínica Alemana de Santiago. Programa de Internado, Facultad de Medicina (NS).

Recibido: 3 de julio de 2012 Aceptado: 26 de diciembre de

Correspondencia a: Raúl Cabrera M rcabrera@alemana.cl

\section{Tinea Nigra: a allochthonous case report in Chile}

Tinea nigra is a superficial mycosis caused by Hortaea werneckii. It is an infrequent asymptomatic infection that affects mainly human palms and soles, and it is mostly seen in tropical countries. It has not been reported in Chile yet. The clinical presentation is generally a single macule, not symptomatic, of brown color in palms and soles. We report a case of a Chilean woman that developed brown macules on both soles after travel to the United States and Central America. The diagnosis of Tinea nigra was confirmed by direct microscopic examination and mycological culture. She had a good response to treatment with oral itraconazol.

Key words: Tinea nigra, skin, Hortaea werneckii, dermatoscopy, Chile.

Palabras claves: Tiña negra, piel, Hortaea werneckii, dermatoscopia, Chile.

\section{Introducción}

L a tiña negra (tinea nigra) es una micosis cutánea superficial causada por Hortaea werneckii, descrita por McGinnis y Schell en $1985^{1}$, anteriormente llamada Phaeoannellomyces werneckii y Exophiala werneckii ${ }^{2}$. La clasificación taxonómica actual de este hongo corresponde a: Reino: Fungi; Phylum: Ascomycota; Clase: Dothideomycetes; Orden: Dothideales y Género: Hortae $^{3,4}$.

La micosis por Hortaea werneckii es poco frecuente, limitada a países tropicales o subtropicales. En algunos centros hospitalarios latinoamericanos representa $0,085 \%$ a $0,1 \%$ del total de micosis registradas ${ }^{5,6}$. Se han comunicado casos aislados en países no endémicos tales como E.U.A ${ }^{7}$, Japón ${ }^{8}$, Argentina ${ }^{9}$ y Uruguay ${ }^{10}$, principalmente en viajeros.

Típicamente se presenta como una mácula única, asintomática, color café o negra, en palmas y menos frecuentemente en plantas ${ }^{2}$. La afectación bilateral es excepcional ${ }^{11,12}$. El diagnóstico es clínico y se confirma mediante un examen micológico directo con hidróxido de potasio y cultivo micológico ${ }^{2}$. La dermatoscopia ayuda en el diagnóstico y permite diferenciarla de otras lesiones pigmentadas ${ }^{13}$.

Se describe un caso diagnosticado en Chile y el método de diagnóstico utilizado.

\section{Caso clínico}

Mujer chilena de 42 años, sin antecedentes mórbidos de importancia, que después de haber realizado viajes cada dos meses y por muchos años a E.U.A y Centroamérica, presentó tres máculas asintomáticas, color café en la planta de los pies.

Al examen físico se observaban tres manchas de 2 a 3 $\mathrm{cm}$., color café claro, con pigmentación y forma irregular, bordes bien definidos, no descamativas y sin signos inflamatorios. Dos lesiones se ubicaban en la planta del pie derecho y una lesión en la planta del pie izquierdo (Figura 1).

La dermatoscopia mostró una lesión no melanocítica, compuesta por una tenue pigmentación café claro homogénea, con múltiples filamentos pequeños de tono café. En algunas zonas la pigmentación se fragmentaba, dejando espacios sin pigmento. La pigmentación se ubicaba principalmente en las crestas papilares (Figura 2).

Se solicitaron exámenes micológicos (examen microscópico directo y cultivo), para lo cual se extrajeron escamas córneas de las tres lesiones por raspado con bisturí estéril, previa limpieza de la zona con alcohol $70 \%$.

$\mathrm{Al}$ examen micológico directo, se depositaron entre lámina y laminilla escamas de la muestra obtenida con una gota de Clorazol Black-E ${ }^{\circledR}$ (Chlorazol fungal stain, Delasco, Council Bluff, IA 51501). Se observaron abundantes hifas septadas ramificadas, tanto hialinas como dematiáceas (Figura 3).

Se cultivó en tres medios distintos: agar Sabouraud dextrosa modificado, agar Sabouraud con cicloheximida y agar Lactrimel, donde fueron inoculadas (en superficie y profundidad) escamas de las muestras obtenidas. Las placas se incubaron a $30^{\circ} \mathrm{C}$ en ambiente húmedo durante un mes. Al cabo de 10 días se observaron pequeñas colonias de aspecto cremoso, color pardo negruzco, que con los días se tornaron negras y brillantes. Después de 30 días de incubación, las colonias presentaban un color 


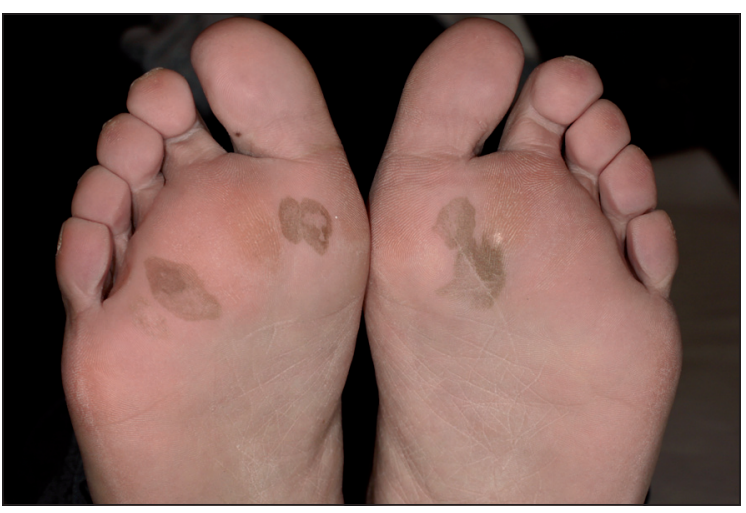

Figura 1. Fotografía clínica de ambas plantas. Se observan manchas de forma irregular, bordes definidos y coloración café, con tonos más oscuros en la periferia y zonas más claras al centro.

negro grisáceo en anverso y reverso de la placa de agar Sabouraud, sin pigmento difusible. En su superficie presentaban pequeñas vellosidades aterciopeladas (Figura 4). Durante el transcurso de esta observación, desde una de estas colonias paralelamente se realizó un microcultivo (cultivo en lámina), donde se observaron hifas septadas dematiáceas y levaduras café de forma elíptica uni y bicelulares, con un septo bien diferenciado de color negro y conidiación anelidica visible. Los conidios inicialmente hialinos, luego se tornaron verde oliva o café. Con los hallazgos macroscópicos y microscópicos obtenidos se identificó la presencia de Hortaea werneckii. Además, sobre algunas colonias se realizaron pruebas fisiológicas de crecimiento con la finalidad de diferenciar la especie. Se demostró tolerancia en medios con $\mathrm{NaCl} 10 \%$, asimilación de lactosa, nitrato y nitrito e inhibición de crecimiento a $37^{\circ} \mathrm{C}$.

La paciente fue tratada con itraconazol $100 \mathrm{mg}$ al día, vía oral, durante cuatro semanas, con remisión completa de la lesión al terminar el tratamiento.

\section{Discusión}

La tiña negra es una infección poco prevalente que ha sido más frecuentemente reportada en Centroamérica, Sudamérica, Asia, y Africa ${ }^{14}$. En Sudamérica se han comunicado varios casos en Brasil ${ }^{15-18}$, además de Argentina ${ }^{9}$, Uruguay $^{10}$, Venezuela ${ }^{6}$ y Perú ${ }^{19}$; sin embargo, no había sido reportada en nuestro país. En Centroamérica, hay casos publicados en México ${ }^{5}$, Panamá ${ }^{20}$ y Costa Rica ${ }^{21}$. La mayoría de los casos encontrados fuera de áreas endémicas han sido resultado de viajes frecuentes o inmigración ${ }^{8}$.

Hortaea werneckii es una especie halofílica, que tiene la capacidad de sobrevivir a altas concentraciones de sal ( $\mathrm{NaCl} 3-30 \%)$, por esta razón los casos encontrados han sido en su mayoría en áreas costeras ${ }^{5}$.

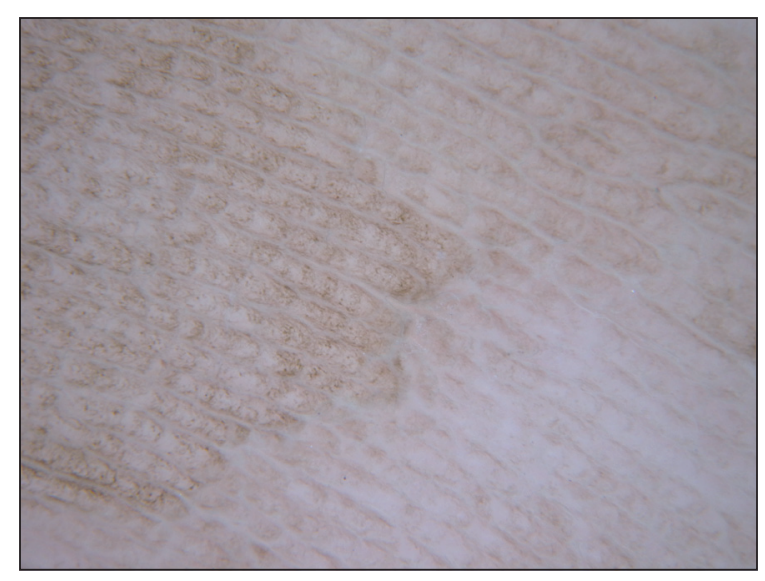

Figura 2. La dermatoscopia muestra múltiples hebras café claras coalescentes, formando una pseudo-red pigmentada. La pigmentación muestra un "patrón de dermatoglifos". (Dermatoscopio Hybrid, 10x).

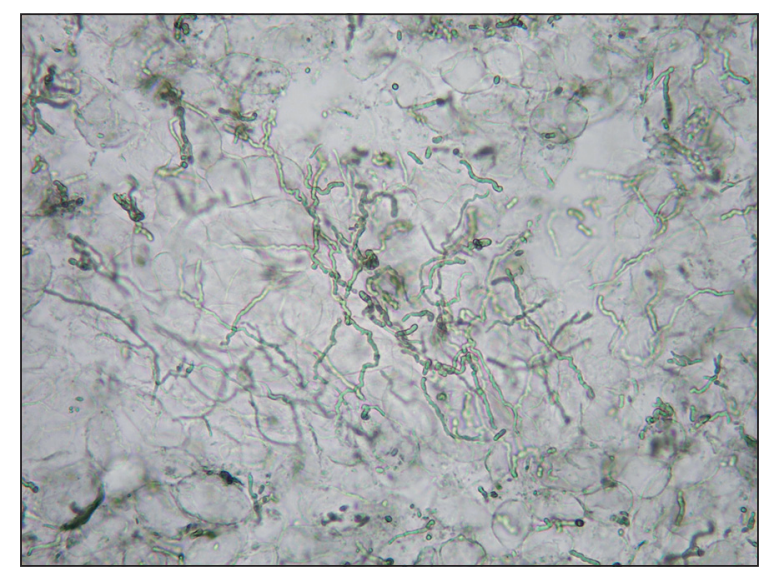

Figura 3. Examen micológico directo. Se observan abundantes hifas septadas ramificadas, tanto hialinas como dematiáceas. La pigmentación de las hifas permite distinguir la tiña negra de otros tipos de dermatofitosis.

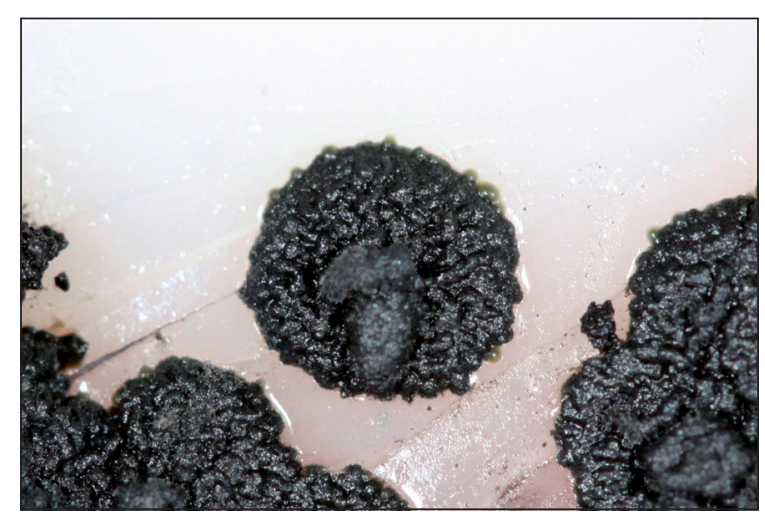

Figura 4. Cultivo. Colonias color negro grisáceo que en su superficie presentan pequeñas vellosidades aterciopeladas.
Se presenta como una infección asintomática, que compromete con mayor frecuencia palmas y plantas, pero también puede encontrarse en zonas cervicales y torácicas ${ }^{22}$. Es más común que sea una lesión única, unilateral, pero pueden presentarse también en ambas extremidades $^{8}$. La presentación bilateral, como nuestro caso, es muy infrecuente, existiendo seis casos publicados en palmas ${ }^{12,16,18}$ y sólo dos casos en la región plantar ${ }^{11,16}$. 
Las lesiones se presentan como máculas o manchas de color negro a café de bordes bien definidos, que crecen lentamente en semanas o meses, de forma centrífuga. Se diferencia de la mayoría de las micosis superficiales en que ésta no es descamativa ni produce prurito ${ }^{14,22}$.

Las lesiones son muy características pero pueden ser mal diagnosticadas como lesiones pigmentadas, y catalogadas como nevus o melanoma maligno, pigmentación post-inflamatoria, erupciones secundarias a fármacos o lesiones químicas como impregnación por uso de nitrato de plata ${ }^{7}$. Algunos autores postulan que un buen examen clínico complementado con un procedimiento no invasor como la dermatoscopia, es más costo-efectivo y puede entregar un diagnóstico tan preciso como el de un procedimiento invasor, para permitir así un tratamiento adecuado $^{13}$.

La apariencia dermatoscópica de la tiña negra es bastante característica, permite sospechar el diagnóstico y diferenciarlo de lesiones pigmentadas. La dermatoscopia muestra espículas pigmentadas, caracterizadas por cadenas finas color café claro que forman una mancha reticulada, usualmente de color café uniforme. Se diferencia de las verdaderas lesiones melanocíticas en que no posee una red pigmentada dermatoscópica. La observación al examen micológico directo y el cultivo característico confirman el diagnóstico definitivo.

El examen micológico directo de una muestra de la lesión, entrega información rápida sobre la presencia de pequeñas hifas delgadas, tortuosas, color café claro que a veces pueden verse más oscuras. La pigmentación de las hifas permite distinguir la tiña negra de otros tipos de dermatofitosis $^{5}$. Si este examen resulta negativo, deben considerarse otras lesiones pigmentarias dentro del diagnóstico diferencial ${ }^{23}$.

Las colonias de Hortaea werneckii crecen en un medio estándar (agar Sabouraud dextrosa) en 5 a 8 días. Inicialmente son negras con una apariencia cremosa y luego se tornan filamentosas. Esta transición morfológica es bastante característica. Las conidias aparecen como células levaduriformes pigmentadas con un septum central oscuro, y luego la pared exterior se adelgaza y pigmenta intensamente. Las conidias finalmente germinan con hifas, resultando en colonias de levaduras que gradualmente evolucionan a filamentos para completar el ciclo $^{5}$.

Respecto del tratamiento, los antifúngicos tópicos son la terapia de elección ${ }^{5,8,19,22,24}$. Se han comunicado casos que respondieron satisfactoriamente a terbinafina ${ }^{25}$, bifonazol $^{8}$, ketoconazol ${ }^{26}$, ciclopirox $^{27}$ y miconazol ${ }^{28}$. Se recomiendan dos a cuatro semanas de tratamiento tópico para obtener una remisión completa ${ }^{5,7,13}$. Otra alternativa es el uso de queratolíticos tópicos como urea, ácido salicílico, pomada de Whitfield (ácido salicílico 3\%, ácido benzoico 2-6\%, en base apropiada como parafina blanca suave) y tretinoina, que reducen la pigmentación ${ }^{13}$. Incluso algunos casos se han resuelto con el solo uso de queratolíticos, aplicándolos una a dos veces al día, con un promedio de 15 días $^{5}$.

Gupta y cols. comunicaron un caso en el cual se utilizó itraconazol oral $200 \mathrm{mg}$ al día, durante tres semanas, logrando una mejoría total del cuadro ${ }^{29}$. Cabe destacar que en este caso, el organismo aislado fue sometido a ensayos de susceptibilidad in vitro, en que se demostró resistencia a fluconazol y sensibilidad a itraconazol, por esta razón se prefirió este último tratamiento ${ }^{29}$. En nuestro caso clínico se utilizó itraconazol vía oral $100 \mathrm{mg}$ al día, durante 4 semanas, obteniendo una remisión completa de la tiña.

\section{Resumen}

La tiña negra (tinea nigra) es una micosis cutánea causada por Hortaea werneckii. Es poco frecuente, limitada a países tropicales o subtropicales. Hasta la presente publicación, esta micosis no había sido comunicada en Chile. La presentación clínica es generalmente una mácula única, asintomática, color café en palmas y plantas. Se presenta el caso de una mujer chilena, que después de varios viajes a E.U.A y Centroamérica, presentó manchas color café en ambas plantas. Se confirmó el diagnóstico de tiña negra con un examen microscópico directo y cultivo micológico. La paciente presentó una buena respuesta clínica luego del tratamiento con itraconazol por vía oral.

\section{Referencias bibliográficas}

1.- McGinnis M R, Schell W A, Carson J. Phaeoannellomyces and the Phaeococcomycetaceae, new dematiaceous blastomycete taxa. Sabouraudia 1985; 23: 179-88.

2.- Vernna S, Hefferman M. Superficial Fungal Infection En: Freedberg IM, Eisen AZ, Wolff $\mathrm{K}$, et al. (eds.) Fitzpatrick's Dermatology in General Medicine $7^{\text {th }}$ ed. New York. McGraw Hill 2008. p. 1807-21.
3.- de Hoog G S, Guarro J, Gené J, Figueras M J. Classification. En: de Hoog GS, Guarro J , Gené J, Figueras M J. Atlas of Clinical Fungi. $2^{\text {nd }}$ ed. Centraalbureau voor Schimmelcultures, Utrecht, The Netherlands, 2000. p.12-20.

4.- NCBI. Taxonomy Browser: Hortaea wernerckii. Disponible en: http://www.ncbi.nlm.nih.gov/ Taxonomy/Browser/wwwtax.cgi?mode=Undef \&id=91943\&lvl=3\&lin=s\&keep=1\&srchmode $=$ 1\&unlock. Accedido: 24 diciembre de 2012.

5.- Bonifaz A, Badali H, de Hoog G S, Cruz M, Araiza J, Cruz M A, et al. Tinea nigra by
Hortaea werneckii, a case report of 22 cases from Mexico. Stud Mycol 2008; 61: 77-82.

6.- Pérez C, Colella M T, Olaizola C, Hartung de Capriles C, Magaldi S, Mata-Essayag S. Tinea nigra: a report of twelve cases in Venezuela. Mycopathologia 2005; 160: 235-8.

7.- Rezusta A, Gilaberte Y, Betran A, Gene J, Querol I, Arias M, et al. Tinea nigra: a rare imported infection. J Eur Acad Dermatol Venereol 2010; 24: 89-91. 
8.- Uezato H, Gushi M, Hagiwara K, Kayo S, Hosokawa A, Nonaka S. A case of tinea nigra palmaris in Okinawa, Japan. J Dermatol 2006; 33: 23-9.

9.- Maldonado I, Fernández L, Leitner R, Vitale R G. Tinea nigra palmaris: presentación de un caso clínico en la República Argentina. Rev Argent Microbiol 2007; 39: 218-20.

10.- Conti-Díaz I A, Burgoa F, Civila E, Bonasse J, Miller A. Tinea nigra. First clinical case in Uruguay. Mycopathologia 1984; 87: 81-3.

11.- Tseng S S, Whittier S, Miller S R, Zalar G L. Bilateral tinea nigra plantaris and tinea nigra plantaris mimicking melanoma. Cutis 1999; 64: 265-8.

12.- Larangeira H, Dallazem R, Sundin L, Ávila da Silva S. Bilateral tinea nigra in a temperate climate. Dermatol Online J 2007; 13: 3.

13.- Piliouras P, Allison S, Rosendahl C, Buettner P, Weedon D. Dermoscopy improves diagnosis of tinea nigra: a study of 50 cases. Australas J Dermatol 2011; 52: 191-4.

14.- Hughes J R, Moore M K, Pembroke A C. Tinea nigra palmaris. Clin Exp Dermatol 1993; 18 : 481-2.
15.- Dinato S L M, Almeida J R P, Romiti N, Camargo F A A. Tinea nigra in the city of Santos: five case reports. An Bras Dermatol 2002; 77: 721-6.

16.- Giraldi S, Abbage K T, Marinoni L P, Oliveira V C, Bertogna J. Tinea nigra: relato de seis casos no Estado do Paraná. An Bras Dermatol 2003; 78: 593-600.

17.- Diniz L M. Estudo de nove casos de tinha negra observados na Grande Vitória (Espírito Santo, Brasil) durante período de cinco anos. An Bras Dermatol 2004; 79: 305-10.

18.- Severo L C, Bassanesi M C, Londero A T. Tinea nigra: report of four cases observed in Rio Grande do Sul (Brazil) and a review of Brazilian literature. Mycopathologia 1994; 126: 157-62.

19.- Bernuy J, Bravo F. Hallazgos dermatoscópicos de tiña nigra: reporte de un caso. Folia Dermatol 2004; 15: 23-5.

20.- Walsh E M. Tinea nigra in Panama. Arch Derm Syphilol 1948; 57: 732.

21.- Marín-Rojas R. First cases of tinea nigra palmaris in Costa Rica. (Original report of cases). Rev Latinoam Microbiol 1972; 14: 25-27.
22.- Charles AJ. Superficial cutaneous fungal infections in tropical countries. Dermatol Ther 2009; 22: 550-9.

23.- Pegas J R, Criado P R, Lucena S K, de Oliveira M A. Tinea nigra: report of two cases in infants. Pediatr Dermatol 2003; 20 : 315-7.

24.- Rossetto A L, Cruz R C. Tinea nigra in geographical forms of "heart" and "parrot beak". An Bras Dermatol 2011; 86: 389-90.

25.- Shannon P L, Ramos-Caro F A, Cosgrove B F, Flowers F P. Treatment of tinea nigra with terbinafine. Cutis 1999; 64:199-201.

26.- Burke W A. Tinea nigra: treatment with topical ketoconazole. Cutis 1993; 52: 209-11.

27.- Rosen $T$, Lingappan A. Rapid treatment of tinea nigra palmaris with ciclopirox olamine gel 0.77\%. Skinmed 2006; 5: 201-3.

28.- Marks J G Jr, King R D, Davis B M. Treatment of tinea nigra palmaris with miconazole. Arch Dermatol 1980; 116: 321-2.

29.- Gupta G, Burden A D, Shankland G S, Fallowfield M E, Richardson M D. Tinea nigra secondary to Exophiala werneckii responding to itraconazole. Br J Dermatol 1997; 137: 483-4. 